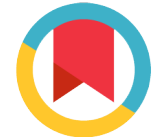

Check for updates
*For correspondence:

sotoodehj2002@yahoo.com

Competing interests: The authors declare that no competing interests exist.

Received: 09 January 2018 Accepted: 08 March 2018 Published: 25 March 2018

Copyright The Author(s) 2018. This article is published with open access by BioMedPress.

This article is distributed under the terms of the Creative Commons Attribution License (CC-BY 4.0) which permits any use, distribution, and reproduction in any medium, provided the original author(s) and the source are credited.

\section{Kisspeptin serum levels in acute myocardial infarction patients and healthy individuals}

\author{
Mohammad Shojaei1, Saeideh Erfanian1, Abdolreza Sotoodeh \\ Jahromi1,* iD, Naeimeh Yusefi2, Abdolhossein Madani³, Masoum \\ Khoshfetrat ${ }^{4}$, Mohammad Hojjat-Farsangi5,6
}

\begin{abstract}
${ }^{1}$ Research Center for non-Communicable Diseases, Jahrom University of Medical Sciences, Jahrom, Iran

2Student Research Committee, Jahrom University of Medical Sciences, Jahrom, Iran ${ }^{3}$ Research Center for Social Determinants of health promotion, Hormozgan University of Medical Sciences, Bandarabbas, Iran

${ }^{4}$ Anesthesiology Department, Zahedan University of Medical Sciences, Zahedan, Iran 5Department of Oncology-Pathology, Immune and Gene therapy Lab, Cancer Center Karolinska (CCK), Karolinska University Hospital Solna and Karolinska Institute, Stockholm, Sweden

6The Persian Gulf Marine Biotechnology Medicine Research Center and Department of Immunology, School of Medicine, Bushehr University of Medical Sciences, Bushehr, Iran
\end{abstract}

\section{Abstract}

Introduction: Acute myocardial infarction (AMI) is a leading cause of mortality worldwide for which several risk factors have been identified. Kisspeptin is a multifunctional peptide observed in atherosclerotic plaques. This study aimed to compare kisspeptin serum levels in AMI patients and healthy individuals. Methods: This case-control study was conducted on patients visiting the Cardiology department of Peymanieh Hospital, Jahrom University of Medical Sciences, Iran. Participants were randomly divided into a case and a control groups; the former consisting of $90 \mathrm{AMI}$ patients and the latter of 90 healthy individuals with no cardiac diseases. Blood samples were collected from the participants who also completed the given questionnaire. The enzyme-linked immunosorbent assay (ELISA) test was used to determine kisspeptin levels following serum separation from collected blood samples. Data analysis was performed in SPSS-19 using descriptive (mean and standard deviation) and analytical (The Mann-Whitney U test) statistical tests. 
Results: The mean age of treatment and control groups was 60.91 and 61.72 years, respectively. The majority (73.3\%) of participants in this study were men. Kisspeptin serum concentrations were demonstrated to be significantly lower in the case group than the control group $(P<0.001)$. The results of MannWhitney $U$ test revealed that kisspeptin serum concentrations of case and control groups did not have a significant relationship with such variables as gender, smoking, and ST-segment elevation and non-ST-segment elevation $(P>0.05)$. Conclusion: The results revealed that kisspeptin serum concentrations of AMI patients were significantly lower than those of healthy individuals. Accordingly, kisspeptin deficiency appears to be a risk factor for AMI. However, due to the multifunctional nature of this peptide, further studies are necessary to discover its precise mechanism of action.

\section{Keywords}

Acute myocardial infarction, Heart disease, Kisspeptin

\section{Introduction}

Cardiac arrest is a major global cause of mortality and disablement. From a pathological perspective, it corresponds to the death of cardiomyocytes due to prolonged ischemia (Apple et al., 2002). The general consensus of basic medical and clinical scientists is that endothelial health plays a fundamental role in the proper functioning of the vascular system in several organs such as the heart, kidney, brain, and lung and in the regulation of vascular tone and hemostatic/fibrinolytic balance. Therefore, any endothelial damage leads to pathogenesis and cardiovascular diseases (Mensah, 2007; Osto et al., 2007). By destroying endothelial cells, vascular trauma or plaque causes an inflammatory response that leads to ischemia (Libby et al., 2010).

Plaques contain blood cells, lipids, proteins, and calcification (Verma et al., 2002). Myocardial infarction is developed due to a combination of environmental factors and individual predispositions (Zimmerman et al., 1995).

Kisspeptin is a protein structure derived from a 145-amino-acid precursor (and encoded by the KISS1 gene) (De Bond and Smith, 2014). Based on immunohistochemical findings, kisspeptin and its receptor have been localized in the brainstem-hypothalamus, spinal cord, pituitary gland, ovarian, prostate (Hesling et al., 2004; Samson et al., 2000), vascular smooth muscles (Maguire et al., 2011), and atherosclerotic plaques (Mead et al., 2007).

In addition, they have been observed in isolated rings of coronary arteries and umbilical vein, with KP-10, KP-13, and KP-54 acting as vasoconstrictors with 
high potencies. The local detection and vasoconstrictor action of kisspeptin in human vascular system suggests that they may act as novel paracrine vascular transmitters as the KISS1 receptor. Discrete localization of kisspeptin receptors along vessels makes them susceptible to atherosclerosis and implicates the pathophysiology of this receptor system in cardiovascular diseases (Mead et al., 2007).

Given the lack of previous research on this topic, the present study aimed to compare kisspeptin serum levels in AMI patients and healthy individuals.

\section{Materials-Methods}

This case-control study was conducted on patients visiting the Cardiology Department of Peymanieh Hospital, Jahrom University of Medical Sciences, Iran. Participants were randomly divided into a case and a control group; the former consisting of $90 \mathrm{AMI}$ patients and the latter of 90 healthy individuals exhibiting no symptoms of cardiac diseases, angina or dyspnea. They had normal electrocardiograms (diagnosed by a cardiologist, based on The World Health Organization standards) and were matched with the treatment group in terms of gender and age.

This study was conducted based on the declaration of Helsinki and approved by the ethics committee of Jahrom University of Medical Sciences. All individuals had consent to participate in study and based on the testimonial they could leave the study.

Blood samples were collected from the participants who also completed the given questionnaire. Blood serum was separated from the collected blood samples and kept at $-70^{\circ} \mathrm{C}$ until serum separation was complete. The ELISA test was conducted on serum samples to determine kisspeptin levels. Data analysis was performed in SPSS ver.19 using descriptive (mean and standard deviation) and analytical (The Mann-Whitney $U$ test) statistical tests.

\section{Results}

The demographic information and biochemical findings of the treatment and control groups are presented in Table 1.

ST-elevation was observed in $82.2 \%$ of participants. Kisspeptin serum concentrations were demonstrated to be significantly lower in the case group than the control group $(P<0.001)$. Moreover, $L D L$ cholesterol $(L D L-C)$ serum concentrations were significantly higher in the case group than the control group $(\mathrm{P}<0.05)$. 
Table 1. Demographic information, clinical characteristics, and laboratory variables of the two groups

\begin{tabular}{|c|c|c|c|}
\hline Variables & Patients group & Control group & P-value \\
\hline Age (year) & $60.91 \pm 10.14$ & $61.72 \pm 10.12$ & 0.112 \\
\hline Male (\%) numbers & $66(73.3 \%)$ & $66(73.30 \%)$ & 0.999 \\
\hline Smoker (\%) numbers & $43(47.8 \%)$ & $39(43.3 \%)$ & 0.549 \\
\hline Diabetes (\%) numbers & $29(32.2 \%)$ & $27(30.0 \%)$ & 0.747 \\
\hline Total cholesterol (mg/dl) & $174.88 \pm 41.30$ & $165.01 \pm 38.49$ & 0.162 \\
\hline HDL-C (mg/dl) & $43.47 \pm 8.81$ & $43.43 \pm 8.96$ & 0.565 \\
\hline LDL-C (mg/d) & $112.07 \pm 32.69$ & $99.01 \pm 31.91$ & 0.007 \\
\hline TG (mg/dl) & $125.11 \pm 66.98$ & $114.50 \pm 51.05$ & 0.551 \\
\hline FBS (mg/d) & $118.71 \pm 33.39$ & $117.72 \pm 38.62$ & 0.683 \\
\hline Serum level of kisspeptin (ng/ml) & $33.89 \pm 19.74$ & $50.43 \pm 25.25$ & $<0.001$ \\
\hline
\end{tabular}

The results of Mann-Whitney $U$ test revealed that kisspeptin serum concentrations of treatment and control groups did not have a significant relationship with such variables as gender, smoking, and ST-elevation and nonST-elevation ( $\mathrm{P}>0.05$ ) (Table 2).

Table 2. Kisspeptin serum concentrations based on the demographic traits of patients and healthy individuals

\begin{tabular}{|c|c|c|c|c|c|}
\hline \multirow{2}{*}{\multicolumn{2}{|c|}{$\begin{array}{l}\text { Groups } \\
\text { Variable }\end{array}$}} & \multicolumn{2}{|l|}{ Case } & \multicolumn{2}{|c|}{ Control } \\
\hline & & \multirow{2}{*}{$\begin{array}{c}\text { Kisspeptin }(\mathrm{ng} / \mathrm{ml}) \\
\text { Mean } \pm \text { SD } \\
34.99 \pm 19.78\end{array}$} & \multirow{3}{*}{$\begin{array}{c}P \text { value } \\
0.382\end{array}$} & \multirow{3}{*}{$\begin{array}{c}\text { Kisspeptin }(\mathrm{ng} / \mathrm{ml}) \\
\text { Mean } \pm \text { SD } \\
48.50 \pm 26.17 \\
55.75 \pm 22.16\end{array}$} & \multirow{3}{*}{$\begin{array}{c}\text { P value } \\
0.231\end{array}$} \\
\hline \multirow{2}{*}{ Gender } & Male & & & & \\
\hline & Female & $30.85 \pm 19.73$ & & & \\
\hline \multirow{2}{*}{ Smoke } & non-smoking & $33.03 \pm 19.65$ & \multirow{2}{*}{0.667} & $49.91 \pm 23.70$ & \multirow{2}{*}{0.825} \\
\hline & smoking & $34.83 \pm 20.03$ & & $51.11 \pm 27.44$ & \\
\hline \multirow{2}{*}{ ST } & nST-MI & $32.40 \pm 22.15$ & \multirow{2}{*}{0.741} & - & \multirow{2}{*}{ - } \\
\hline & ST-MI & $34.21 \pm 19.33$ & & - & \\
\hline
\end{tabular}




\section{Discussion}

Based on previous studies on kisspeptin, the present research sought to compare kisspeptin serum concentrations of $\mathrm{AMI}$ patients and healthy individuals for the first time.

The results revealed that serum level changes did not have a significant relationship with age. In a study titled "Plasma Kisspeptin-54 Levels in Gastric Cancer Patients", Ergen et al., demonstrated that kisspeptin serum levels did not have a significant relationship with age (Ergen et al., 2012), which is in line with the present study. In another study by Sesti et al., on the relationship between plasma kisspeptin levels in non-diabetic individuals with insulin secretion, plasma kisspeptin levels were shown to be significantly and positively related to age (Andreozzi et al., 2017) which is inconsistent with the results of the present study.

Similarly, Gong et al., determined the changes of serum leptin and kisspeptin levels in Chinese children and adolescents in different pubertal stages. Their results indicated that serum kisspeptin levels were positively related to the age of participants (Pan et al., 2016).

These discrepancies may be attributed to the age-heterogeneous populations of these studies as well as other inherent characteristics. Moreover, Kisspeptin serum concentrations of the two groups did not have a significant relationship with gender. In a similar vein, Ergen et al., did not find a significant relationship between kisspeptin serum levels and gender (Ergen et al., 2012), which corresponds to the results of the present study.

In addition, kisspeptin serum concentrations of the treatment and control groups did not have a significant relationship with smoking. In a study conducted by Jayasena et al., on the effect of kisspeptin on miscarriage, smoking by pregnant women was demonstrated to not have a significant relationship with kisspeptin serum levels (Prague and Dhillo, 2015), which is consistent with the present study.

Finally, LDL-C serum levels of AMI patients were higher than those of healthy individuals. In another study aimed at comparing lipid profiles in patients with $\mathrm{AMI}$ and unstable angina pectoris, Amouzadeh et al., observed higher LDL-C serum levels in AMI patients than those with unstable angina pectoris (Amozadeh et al., 2010). Since abnormal lipid concentration is a major risk factor for cardiovascular diseases, the higher LDL-C serum levels in AMI patients compared with healthy individuals is reasonable. 


\section{Conclusion}

The results revealed that kisspeptin serum concentrations of $\mathrm{AMI}$ patients were significantly lower than those of healthy individuals, which could be used to argue that low kisspeptin serum levels in AMI patients might prove risky. Since kisspeptin is a multifunctional peptide (Prague and Dhillo, 2015), more extensive results are required to understand the complex pathways regulated by this peptide and the way these pathways are combined within the entire human body system by considering the various functional roles it plays.

\section{Abbreviations}

AMI: Acute myocardial infarction

FBS: Fasting Blood Sugar

HDL-C: high density lipoprotein- cholesterol

LDL-C: low density lipoprotein- cholesterol

NST-MI: Non ST-elevation myocardial infarction

ST-MI: ST-elevation myocardial infarction

TG: Triglyceride

\section{Acknowledgements}

Special thanks to Jahrom University of Medical Sciences for the support on foundation. This Article Has been extracted from Mrs Naeimeh Yusefi's Medical Doctor (MD) thesis from Jahrom University of Medical Sciences.

\section{Author Contribution}

Mohammad Shojaei: Design of study, proposal of study writing, final content of study. Abdolreza Sotoodeh Jahromi, Saeideh Erfanian, Naeimeh Yusefi: proposal of study writing, interpretation, final content of study. Abdolhossein Madani: proposal of study writing, enrolled data, manuscript writing/ Mohammad Hojjat-Farsangi: Design of study, proposal of study writing, analysis, interpretation, manuscript writing, final content of study. All authors read and approved the final version of manuscript.

\section{References}

Amozadeh, K., Saravi, M., Abrotan, S., \& Amiri, M. (2010). Serum levels of LP (a) with LDL, VLDL, and HDL in 218 hospitalized cases with AMI or UA. [CJIM]. Caspian Journal of Internal Medicine, 1, 12-15.

Andreozzi, F., Mannino, G. C., Mancuso, E., Spiga, R., Perticone, F., \& Sesti, G. (2017). Plasma kisspeptin levels are associated with insulin secretion in nondiabetic 
individuals. PLoS One, 12(6), e0179834. https://doi.org/10.1371/journal.pone.0179834 PMID:28636637

Apple, F. S., Wu, A. H., \& Jaffe, A. S. (2002). European Society of Cardiology and American College of Cardiology guidelines for redefinition of myocardial infarction: How to use existing assays clinically and for clinical trials. American Heart Journal, 144(6), 981-986. https://doi.org/10.1067/mhj.2002.124048 PMID:12486421

De Bond, J.-A. P., \& Smith, J. T. (2014). Kisspeptin and energy balance in reproduction. Reproduction (Cambridge, England), 147(3), R53-R63. https://doi.org/10.1530/ REP-13-0509 PMID:24327738

Ergen, A., Canbay, E., Bugra, D., Zeybek, U., Yamaner, S., \& Bulut, T. (2012). Plasma Kisspeptin-54 levels in gastric cancer patients. International Journal of Surgery, 10(9), 551-554. https://doi.org/10.1016/j.jjsu.2012.08.014 PMID:22959969

Hesling, C., D'Incan, M., Mansard, S., Franck, F., Corbin-Duval, A., Chèvenet, C., . . . Bignon, Y. J. (2004). In vivo and in situ modulation of the expression of genes involved in metastasis and angiogenesis in a patient treated with topical imiquimod for melanoma skin metastases. British Journal of Dermatology, 150(4), 761-767. https:// doi.org/10.1111/j.0007-0963.2004.05898.x PMID:15099376

Libby, P., Okamoto, Y., Rocha, V. Z., \& Folco, E. (2010). Inflammation in atherosclerosis: Transition from theory to practice. Circulation Journal, 74(2), 213-220. https://doi.org/ 10.1253/circj.CJ-09-0706 PMID:20065609

Maguire, J. J., Kirby, H. R., Mead, E. J., Kuc, R. E., d'Anglemont de Tassigny, X., Colledge, W. H., \& Davenport, A. P. (2011). Inotropic action of the puberty hormone kisspeptin in rat, mouse and human: Cardiovascular distribution and characteristics of the kisspeptin receptor. PLoS One, 6(11), e27601. https://doi.org/10.1371/journal.pone.0027601 PMID:22132116

Mead, E. J., Maguire, J. J., Kuc, R. E., \& Davenport, A. P. (2007). Kisspeptins are novel potent vasoconstrictors in humans, with a discrete localization of their receptor, $G$ protein-coupled receptor 54, to atherosclerosis-prone vessels. Endocrinology, 148(1), 140-147. https://doi.org/10.1210/en.2006-0818 PMID:17023533

Mensah, G. A. (2007). Healthy endothelium: The scientific basis for cardiovascular health promotion and chronic disease prevention. Vascular Pharmacology, 46(5), 310314. https://doi.org/10.1016/j.vph.2006.10.013 PMID:17229594

Osto, E., Coppolino, G., Volpe, M., \& Cosentino, F. (2007). Restoring the dysfunctional endothelium. Current Pharmaceutical Design, 13(10), 1053-1068. https://doi.org/ 10.2174/138161207780487566 PMID:17430168

Zhu, H. J., Li, S. J., Pan, H., Li, N., Zhang, D. X., Wang, L. J., . . Gong, F. Y. (2016). The Changes of Serum Leptin and Kisspeptin Levels in Chinese Children and Adolescents in Different Pubertal Stages. International Journal of Endocrinology, 2016, 6790794. https://doi.org/10.1155/2016/6790794 PMID:27990162

Prague, J. K., \& Dhillo, W. S. (2015). Potential clinical use of kisspeptin. Neuroendocrinology, 102(3), 238-245. https://doi.org/10.1159/000439133 PMID: 26277870

Samson, W. K., Resch, Z. T., \& Murphy, T. C. (2000). A novel action of the newly described prolactin-releasing peptides: Cardiovascular regulation. Brain Research, 858(1), 19-25. https://doi.org/10.1016/S0006-8993(99)02451-8 PMID:10700591

Verma, S., Wang, C.-H., Li, S.-H., Dumont, A. S., Fedak, P. W., Badiwala, M. V., . . Stewart, D. J. (2002). A self-fulfilling prophecy: C-reactive protein attenuates nitric oxide production and inhibits angiogenesis. Circulation, 106(8), 913-919. https://doi.org/ 10.1161/01.CIR.0000029802.88087.5E PMID:12186793 


\section{Biomedical}

Research \& Therapy
ISSN: $2198-4093$

www.bmrat.org

Zimmerman, F. H., Cameron, A., Fisher, L. D., \& Ng, G. (1995). Myocardial infarction in young adults: Angiographic characterization, risk factors and prognosis (Coronary Artery Surgery Study Registry). Journal of the American College of Cardiology, 26(3), 654-661. https://doi.org/10.1016/0735-1097(95)00254-2 PMID:7642855 